\title{
Ernesto Nazareth e a valsa da Suite Retratos de Radamés Gnattali
}

\author{
Luciano Chagas Lima (Université de Montréal, Canadá) \\ limaguitar@gmail.com
}

\begin{abstract}
Resumo: Composta por Radamés Gnattali (1906-1988) em 1956 para bandolim solista, conjunto de choro e orquestra de cordas, Retratos é uma suite em quatro movimentos onde são homenageadas algumas das mais expressivas personalidades do cenário da música popular brasileira: Pixinguinha, Ernesto Nazareth, Anacleto de Medeiros e Chiquinha Gonzaga. 0 que dá forma e sustenta a narrativa da obra é a ideia de que os movimentos constituem retratos musicais destes compositores. Assim, a estrutura de cada movimento foi elaborada a partir de um modelo, ou seja, de cada compositor Gnattali escolheu uma peça que serviria de roteiro para o processo criativo dos retratos. Este estudo tem como foco o segundo movimento da suite, a valsa, observando como está relacionado ao seu respectivo modelo, a valsa Expansiva de Ernesto Nazareth (1863-1934). Para ilustrar o paralelo será apresentada uma análise mais comparativa do que formal, procurando ampliar a visão do contexto histórico com evidências musicais, concentrando-se principalmente nos elementos comuns a ambas as peças.
\end{abstract}

Palavras-chave: Radamés Gnattali; Ernesto Nazareth; valsa; Retratos; Expansiva.

\section{Ernesto Nazareth and the waltz from Radamés Gnattali's Suite Retratos}

Abstract: Written in 1956 by Brazilian composer Radamés Gnattali (1906-1988) for solo mandolin, choro ensemble and strings orchestra, Retratos (namely, Portraits in Portuguese) is a four movement suite that pays homage to some of the most significant personalities in the history of Brazilian popular music: Pixinguinha, Ernesto Nazareth, Anacleto de Medeiros and Chiquinha Gonzaga. What shapes and supports the suite's narrative is the idea that the movements represent musical portraits of these composers. As a result, each movement was structured after a model, that is, Gnattali has chosen a particular piece by each composer that would serve as a blueprint for the creative process of the portraits. The focus of this study is the suite's second movement, the waltz, observing how it is related to its respective model, the waltz Expansiva by Ernesto Nazareth (1863-1934). In order to illustrate this parallel, a more comparative than formal analysis will be provided, in an attempt to expand the view from the historical context to musical facts, drawing special attention to all cross-references present in the work.

Keywords: Radamés Gnattali; Ernesto Nazareth; waltz; Retratos; Expansiva.

\section{1- Introdução}

Uma das obras mais significativas da produção de Radamés Gnattali, Retratos é uma suíte em quatro movimentos onde são homenageados quatro grandes representantes da cultura musical brasileira: Pixinguinha, Ernesto Nazareth, Anacleto de Medeiros e Chiquinha Gonzaga. A escolha destes compositores justifica-se também pelo fato de cada um deles simbolizar um estilo, ou melhor, pelo fato de suas trajetórias musicais revelarem obras que podem ser consideradas como paradigmas de um determinado estilo. Assim, Pixinguinha entra como o representante maior do choro; Nazareth através da elegância de suas valsas; Anacleto, maestro da Banda do Corpo de Bombeiros, famoso pelos seus schottisches; e Chiquinha Gonzaga, "a primeira chorona e primeira pianeira" (CA-
ZES, 1998, p.35), com o elemento do maxixe. A escolha destes quatro estilos pode ser interpretada também como uma breve amostra de alguns dos vários elementos que definiram o perfil da música brasileira: o choro como o principal símbolo da música urbana; a herança europeia representada pela valsa e pelo schottisch; e o ingrediente africano presente no rítmico corta jaca. Definida a estrutura da suite, os movimentos de Retratos foram designados da seguinte forma: I - Pixinguinha (choro); II - Ernesto Nazareth (valsa); III - Anacleto de Medeiros (schottisch); IV - Chiquinha Gonzaga (corta jaca). Dito isto, cabe aqui esclarecer que toda menção ao nome de Ernesto Nazareth ao longo do texto refere-se ao compositor e não ao título do segundo movimento da suíte. 
Vale ainda observar que:

\begin{abstract}
...a escolha dos homenageados também está de acordo com o formato de uma suite, combinando complexidade, diferentes texturas e andamentos em uma coleção de padrões ritmicos contrastantes, evocando de alguma forma o elemento de dança presente em uma suite barroca (LIMA, 2008, p.1).
\end{abstract}

Mas o que caracteriza a essência de Retratos é o fato de cada movimento ser baseado em um modelo. Gnattali escolheu de cada compositor uma determinada peça que serviria de roteiro para o processo criativo dos retratos; seguindo este princípio, o primeiro movimento foi construído a partir do choro Carinhoso, de Pixinguinha; o segundo elaborado sobre a valsa Expansiva, de Ernesto $\mathrm{Na}$ zareth; o terceiro sobre Três Estrelinhas, de Anacleto de Medeiros; e o quarto movimento sobre o maxixe Gaúcho, também conhecido como Corta Jaca, de Chiquinha Gonzaga. É importante ressaltar que os movimentos da suite de forma alguma podem ser qualificados como arranjos ou que foram meramente "inspirados" nestas peças. Gnattali explora sim os modelos à risca, mas transforma os elementos originais e dá a Retratos uma identidade própria que a sustenta como obra artística. Presente no dia da gravação, uma tarde chuvosa de quinta-feira, o jornalista e musicólogo Lúcio Rangel observa:

$\mathrm{Na}$ "suite", os retratos são padrões de originalidade e, ao mesmo tempo, dão ideia perfeita de quatro grandes músicos que são Pixinguinha, Anacleto de Medeiros, Ernesto Nazareth e Chiquinha Gonzaga. Não direi que Radamés dignificou esses músicos já digníssimos: compreendeu, que é melhor. E criou, não "à manière de", mas na maneira de Radamés (RANGEL in GNATTALI, 1964, CBS 60099).

Escrita originalmente para bandolim solista, orquestra de cordas e conjunto regional, Retratos não deixa também de fazer alusão à forma concerto. Em uma crítica sobre a suite, o crítico e musicólogo Eurico Nogueira França comentou que Radamés Gnattali havia composto "uma espécie de concerto - sem buscar nenhuma espécie de ligação com o conceito tradicional da forma" (apud BARBOSA, 1984, p.66). Até mesmo na contracapa do disco da primeira gravação (GNATTALI, 1964, CBS 60099) consta a inscrição "Concerto para bandolim, orquestra de cordas, violão e cavaquinho". Mas, segundo Hermínio Bello de Carvalho, Radamés não aprovava o título de "Concerto", dado à sua revelia, e preferia ver Retratos denominada como "Suite". "Concerto ou Suite? Música, eis tudo" (CARVALHO in GNATTALI, 1980, Atlantic BR 20.055). Retratos teve desde então uma série de versões, sendo arranjada pelo próprio compositor para a Camerata Carioca; piano e orquestra; orquestra sem solista; dois violões; três violões; para o seu quinteto (dois pianos, baixo, guitarra e bateria); além de inúmeros arranjos elaborados por outros músicos. A partitura utilizada como referência neste estudo é a da versão para dois violões (Ed. Sérgio e Odair Assad) publicada pela casa editora Henry Lemoine, Paris.

Radamés conviveu ao longo da sua carreira com a "fina flor dos intérpretes brasileiros" (BARBOSA, 1984, p.65), dos quais alguns, além de grandes instrumentistas, eram também amigos próximos do compositor. Nas palavras no próprio Gnattali: "eu sempre escrevi música para os meus amigos. Quando eu compunha uma peça para vioIoncelo, era para Iberê [Gomes Grosso] tocar. Ele tinha muita bossa, muito jeito para música brasileira" (BARBOSA, 1984, p.65). A Suíte Retratos foi então dedicada a Jacob Bittencourt, mais conhecido como Jacob do Bandolim, um ícone da história do choro por quem Gnattali tinha muito apreço. A primeira audição deu-se na Rádio Nacional, curiosamente tendo como solista não Jacob e nem sequer um bandolinista, mas Romeu Seibel, o Chiquinho do Acordeon, que executou a parte do bandolim ao acordeon. Após um decurso de oito anos desde a composição em 1956, a estreia oficial aconteceu no dia 24 de agosto de 1964, ocasião do lançamento da gravação realizada seis meses antes, no saguão do Museu Nacional de Belas Artes, no Rio de Janeiro, tendo Jacob como solista e Gnattali como regente.

\section{2- Ernesto Nazareth}

Compositor e pianista, Ernesto Nazareth nasceu no Rio de Janeiro no dia 20 de março de 1863. Iniciou os estudos de piano com sua mãe, aperfeiçoando-se mais tarde com Eduardo Madeira e Lucien Lambert que Ihe transmitiu um profundo entendimento da música de Chopin, uma grande influência na sua obra. Enfrentando sérios problemas de saúde mental, Nazareth foi internado na Colônia Juliano Moreira, em Jacarepaguá, vindo a falecer no início de fevereiro de 1934.

Nazareth teve uma participação marcante na cena musical do Rio de sua época, onde "seus tangos foram executados e gostados, se espalharam, e o compositor teve a glória de ser tão familiar na pátria inteirinha [...]" (ANDRADE, 1926, p.121). E um dos espaços a acolher e fazer as honras de vitrine para a música de Nazareth foi o Cine Odeon. Inaugurado em 1909, este lugar logo se instaurou como um pólo cultural que reunia a elite da época.

Dentro de um programa de 'atrações', as empresas exibidoras davam-se ao luxo de apresentar ao público, na 'sala de espera', audições com os melhores conjuntos musicais, que em tournées passavam pelo Rio [...] e, como atração nacional,[...] Ernesto Nazareth. Sua presença no Odeon tornou-se acontecimento significativo para a vida musical da cidade. Havia muita gente que comprava o ingresso e, em lugar de entrar nas salas de projeção, ficava ali, junto do estrado, a ouvi-lo tocar horas a fio (PINTO, 1963, p.41).

Dentre as personalidades de destaque que frequentavam o cinema e que apreciavam a música de Nazareth, figuravam Ruy Barbosa, Darius Milhaud, Henrique Oswald, Villa-Lobos, Arthur Rubinstein, Tomás Téran, entre outros. Mas também havia gente que, sem recursos para pagar o ingresso, ouvia Nazareth do lado de fora do cinema. Conforme observa BARBOSA (1984, p.17), "ouvir Ernesto Nazareth 'do lado de fora' do cinema Odeon foi para Radamés, se não o ideal, o suficiente para perceber todas as nuances de interpretação daquele já consagrado pianista". Mas, como prova o testemunho abaixo, o contato de Gnattali não se restringiu à distância do espectador sem ingresso: 
Foi em 25 ou 26, no Cinema Odeon, na Rio Branco esquina com Sete de Setembro. Eu vinha andando pela avenida e ouvi um som de piano. Era o Nazareth tocando e eu já conhecia as músicas dele. Nazareth tocava num piano de armário em cima de um estrado, perto de umas cadeiras de veludo, atrás de uma parede de vidro na sala de espera. Toquei várias vezes pra ele (Gnattali citado por DIDIER, 1996, p.75-76)

Gnattali tanto admirava a música de Nazareth que gravou em 1954 um disco dedicado exclusivamente à obra do pianista (Continental LP-V-2001). 0 repertório incluia Expansiva, Tenebroso, Ameno Resedá, Odeon, Fon-Fon, Apanhei-te Cavaquinho, Confidências e Batuque. Coincidentemente, outro grande admirador da arte de Nazareth foi Jacob do Bandolim. Segundo PAZ (1997, p.98), "para ele, Nazareth não apenas fotografou e criou a alma brasileira. 'Ele foi mais eclético. Foi mais além das nossas fronteiras. 0 fraseado dele é uma coisa muito mais ampla do que os limites do Brasil'". Jacob não só estudava a fundo a obra de Nazareth, como provam as análises, notas e observações feitas pelo bandolinista nas partituras encontradas no seu arquivo, mas também, "das coisas mais simples às mais complexas, seu forte compromisso com a verdade levou-o, como no caso de Ernesto Nazareth, a desvendar os mistérios que cercaram sua morte" (PAZ, 1997, p.25). Como intérprete, Jacob foi um grande divulgador da obra de Nazareth, incluindo várias composições do pianista em discos seus, com destaque para Jacob Revive Músicas de Ernesto Nazareth (RCA Victor BP-1) de 1952.

\section{3- Elementos comuns entre a valsa de Retra- tos e Expansiva}

Nazareth compôs diversas peças dentro dos diferentes estilos em voga na sua época, tangos brasileiros, polcas, choros, mas talvez o que pudesse melhor representar "a força conceptiva, a boniteza da invenção melódica, [e] a qualidade expressiva" (ANDRADE, 1926, p.124) da sua música fosse a valsa. Dentre as suas 41 valsas, Gnattali escolheu Expansiva para servir como modelo para o segundo retrato da suíte. Curiosamente, esta valsa é a peça que abre o disco gravado por Gnattali acima mencionado, sendo também gravada por Jacob em 1960 no disco Valsas Brasileiras de Antigamente. Apesar da manifesta influência de Chopin na obra de Nazareth, Expansiva parece ter sido inspirada em uma peça de outro grande compositor do universo pianístico, Liebestraum n.3 do húngaro Franz Liszt. Mas isto é objeto para um futuro estudo, já que uma análise mais detalhada sobre o assunto foge do âmbito desta pesquisa.

Escrita em 1912, Expansiva apresenta a estrutura de um rondó de três partes, uma forma típica da tradição do choro. A tonalidade original é Ré bemol maior, dando sequência a um esquema harmônico onde a segunda e terceira partes exploram o quinto e quarto graus (Lá bemol maior e Sol bemol maior), respectivamente. Com relação à quadratura, as frases em Expansiva são organizadas em dois grupos de dezesseis compassos, onde o primeiro assume uma função de antecedente, encerrando com uma cadência imperfeita, e o segundo representa o com- plemento consequente, repetindo parte do conteúdo do primeiro grupo e concluindo com uma cadência perfeita.

Gnattali mantém na valsa da Suite Retratos estes traços formais que definem o contorno de Expansiva, porém vistos através de um viés diferente. Talvez a principal diferença em termos estruturais seja a presença de uma introdução e uma Codeta, assim como realizado no primeiro movimento da suite. No entanto, esta Codeta não passa de uma variação dos cinco últimos compassos da seção $A$, sendo inserida no mesmo ponto estrutural, completando o arco de trinta e dois compassos. A forma rondó é preservada, apresentando apenas algumas alterações: ao passo que Nazareth faz uma repetição literal do $A$ após 0 B em Expansiva, Gnattali apresenta na valsa da suite uma versão transformada e abreviada deste segundo $A_{\text {, con- }}$ tendo apenas dezesseis compassos. Finalmente, a terceira parte da valsa de Retratos possui um ritornello que não ocorre em Expansiva. Assim, as estruturas de ambas as peças poderiam ser resumidas da seguinte forma:

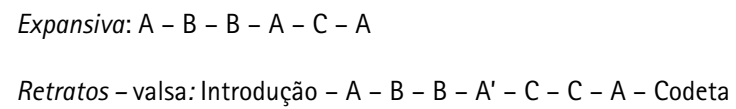

Tendo em vista um resultado mais idiomático, a tonalidade original de Expansiva foi transposta para Dó maior na valsa da suite, favorecendo assim uma textura mais apropriada para o bandolim que segue o mesmo padrão de afinação do violino em intervalos de quinta (Sol, Ré, Lá, Mi). Todavia, Gnattali em nada altera o esquema harmônico original, mantendo a mesma proporção do quinto e quarto graus para a segunda e terceira partes de sua valsa. Já no tocante à quadratura das frases, apesar de Gnattali preservar a mesma moldura de dois grupos de dezesseis compassos em cada parte, a valsa da suíte não apresenta exatamente a mesma simetria de Expansiva.

Após a introdução, da qual trataremos mais adiante, a exposição da valsa de Retratos é claramente derivada do modelo original, com a longa sustentação da terça na melodia (Ex.1 e Ex.2). Visando ilustrar com mais clareza o paralelo proposto neste estudo, todos os exemplos a seguir terão Expansiva transposta meio tom abaixo.

Com relação ao contorno descendente do baixo, em Expansiva esta linha combina posições fundamentais com inversões, partindo de um Dó para um Mi uma sexta menor abaixo, resultando em um total de sete compassos. Já na valsa de Retratos, esta linha é transformada e comprimida em uma unidade de três compassos, mas preserva ainda o mesmo intervalo de sexta menor.

No entanto, apesar de ambas as peças compartilharem a mesma ideia desta linha de baixo descendente, na valsa da suite os acordes estão todos em posição fundamental. Mas tanto Nazareth quanto Gnattali incorporam neste trecho uma nota de passagem não pertencente à escala da primeira parte: o acorde diminuto no terceiro compasso de Expansiva e o acorde de F\#m7(b5) no segundo compasso 


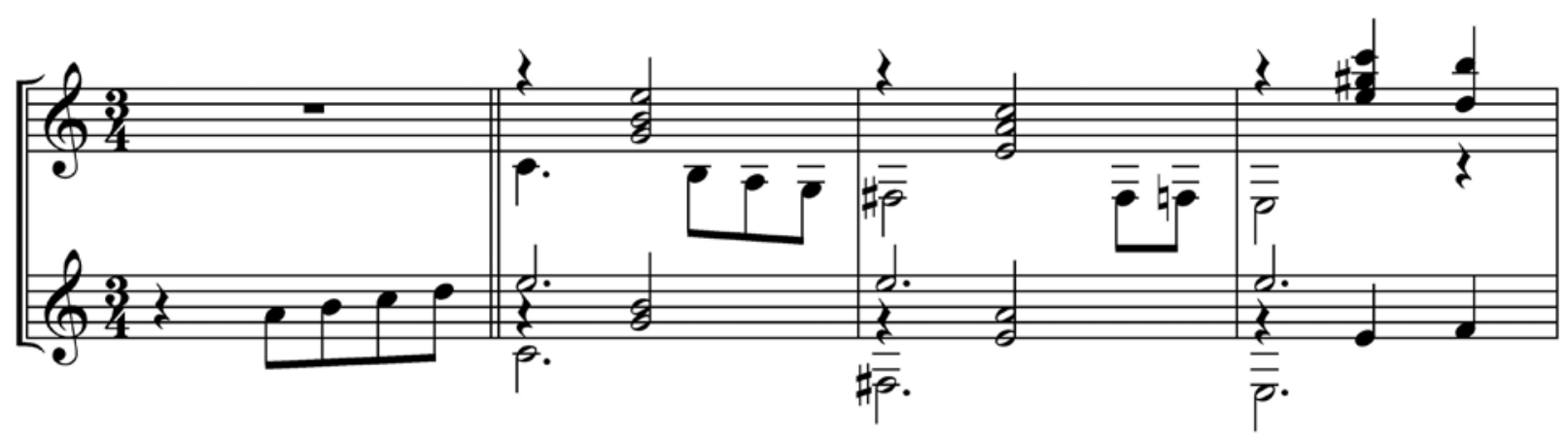

Ex.1: Retratos - valsa c.19-22 (início da seção A)

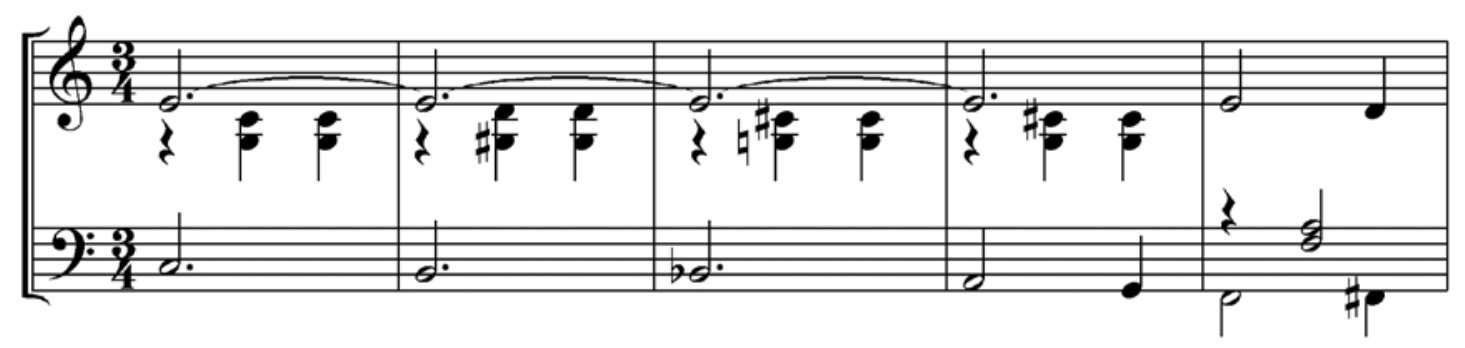

Ex.2: Expansiva c.1-5 (início da seção A)

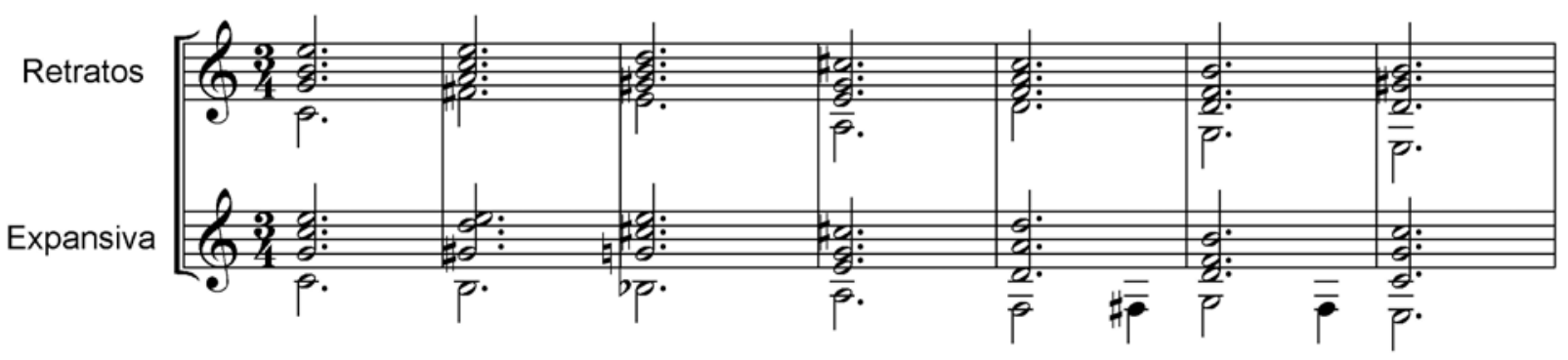

Ex.3: Harmonia dos sete primeiros compassos da exposição da valsa de Retratos (c.20-26) e Expansiva (c.1-7)

da exposição da valsa de Retratos (ver Ex.1 e Ex.2). Em relação à distância entre a tônica inicial e a nota de passagem, 0 acorde diminuto de Expansiva está um tom abaixo da tônica; na valsa de Retratos, embora a linha descendente do baixo esteja comprimida, Gnattali estende esta diferença, aumentando o intervalo para uma quinta diminuta abaixo. Salvo algumas alterações, o tratamento harmônico de ambas as peças é bastante similar (Ex.3).

Após praticamente citar os compassos iniciais de Expansiva, a valsa Retratos explora um conteúdo melódico inteiramente novo sustentado por um conceito harmônico diferenciado. Ao atingir o ponto estrutural de uma esperada repetição na primeira parte, precisamente após o primeiro grupo de dezesseis compassos onde Expansiva repete literalmente o mesmo material de seus primeiros oito compassos, Gnattali dá sequência ao segundo grupo com uma versão transformada deste material (Ex.4).
Um detalhe interessante deste trecho é que, estendendo a linha do baixo no âmbito de uma oitava (Ex.4 pentagrama superior), Gnattali de certa forma retifica não só o cromatismo delineado no baixo dos quatro primeiros compassos de Expansiva, mas também a compressão da ideia original discutida anteriormente. Retornando à introdução, é possível observar que ela contém suas próprias referências cruzadas, sendo de certa forma um sumário de toda a estrutura da peça. A anacruse em colcheias, que é um material novo não derivado do modelo, é um dos motivos centrais da introdução (Ex.5). Aliás, esta é uma diferença marcante entre a valsa de Retratos e Expansiva, sendo que a última começa todas as três partes de forma tética enquanto que Gnattali usa o impulso de uma anacruse para cada parte.

Após estes compassos iniciais, a sequência descendente de acordes pode ser relacionada à linha descendente do 


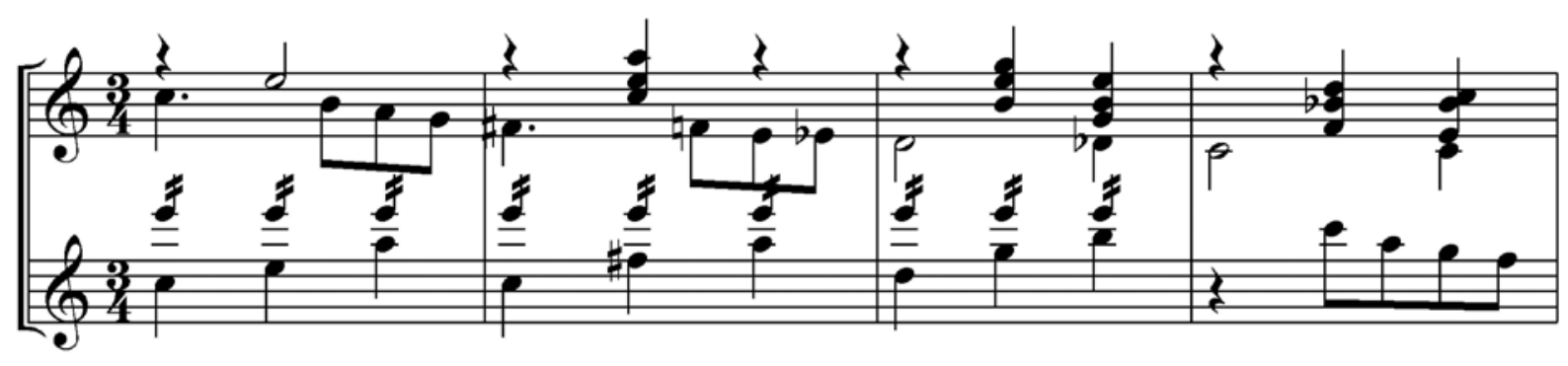

Ex.4: Retratos - valsa c.36-39 (início do segundo grupo)

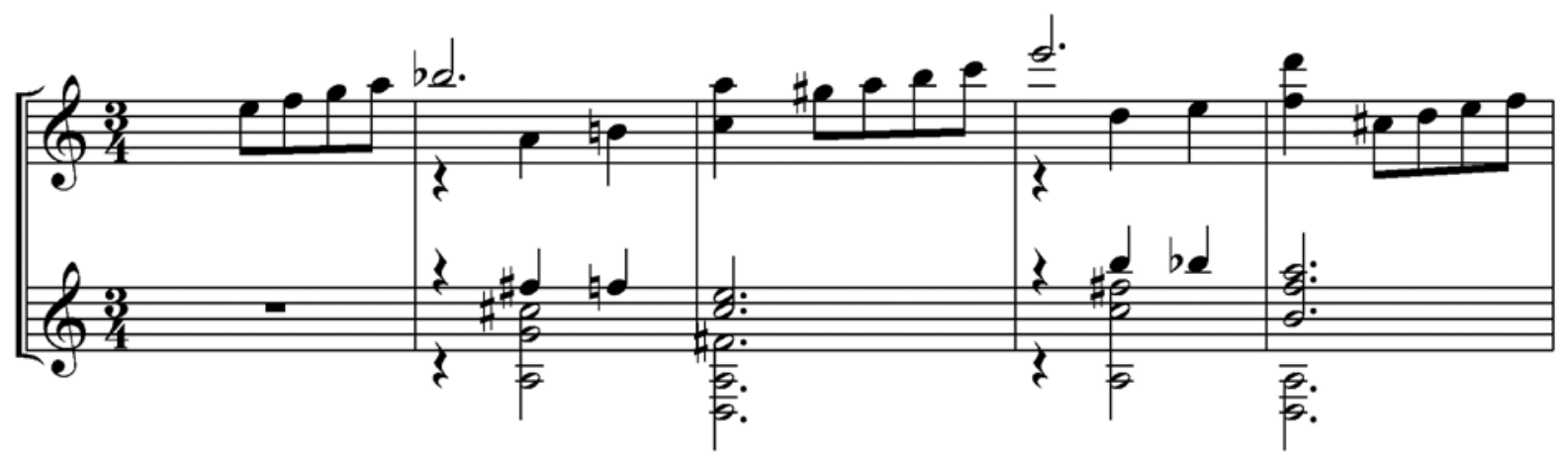

Ex.5: Retratos - valsa c.1-5 (introdução - anacruse)

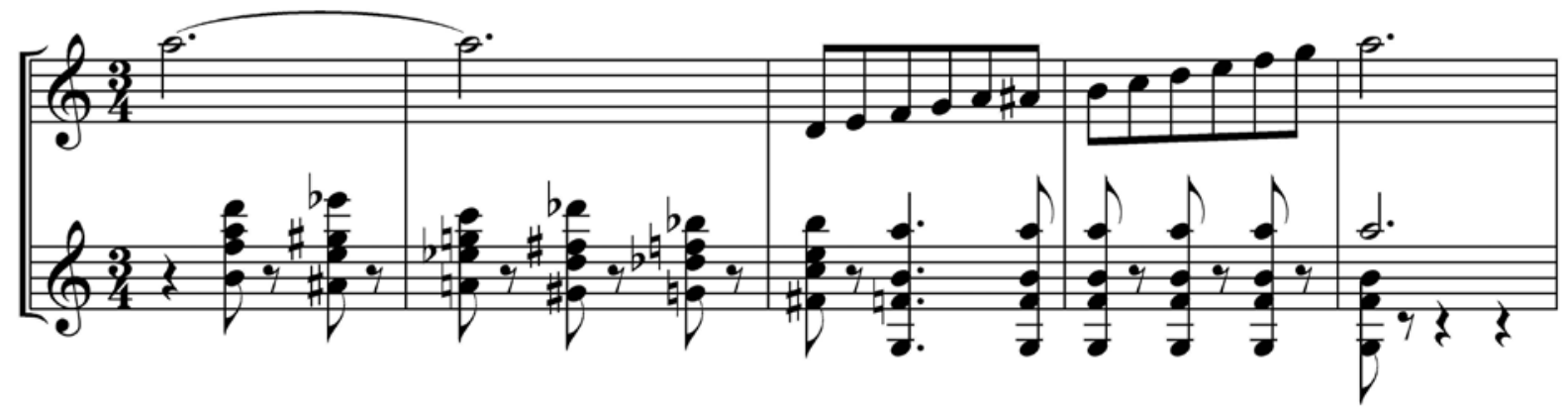

Ex.6: Retratos - valsa c.6-10 (introdução - acordes descendentes)

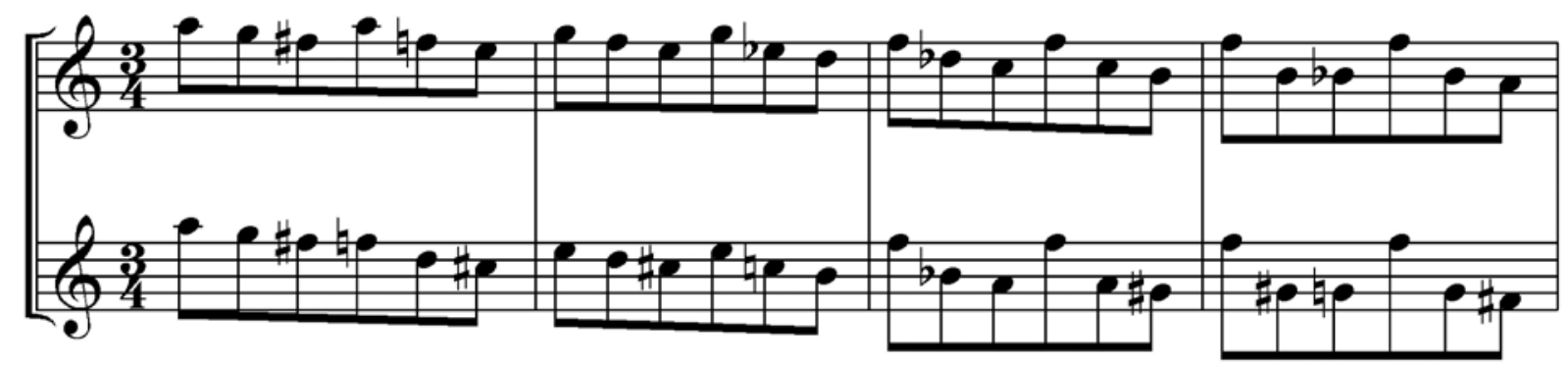

Ex.7: Retratos - valsa c.11-14 (final da introdução) 
baixo na seção A que, assim como na exposição, serve também como um tapete harmônico para a nota longa sustentada da melodia (Ex.6 c.6-7). Em seguida, a figura pontuada (Ex.6 c.8-9) pode ser encarada como uma referência ao ritmo empregado no início da seção $B$.

Finalmente, encerrando a introdução, há um movimento melódico com um caráter quase cadencial articulado em dois grupos de colcheias, como em um compasso de 6/8, antecipando o contorno que será usado na terceira parte (Ex.7). Dando continuidade à análise, a segunda parte da valsa da suíte tem início com uma anacruse, assim como ocorre nas demais seções. A seguir, a inflexão rítmica é idêntica ao modelo original, mas agrupada de um modo diferente: em Expansiva há uma ideia básica encerrada em um grupo de dois compassos (Ex.9 c.33-34, c.35-36, etc.) ao passo que na valsa da suíte esta ideia é expandida para um grupo de quatro compassos (Ex.8 c.52-55, etc.).

A figura rítmica pontuada e a escala ascendente em colcheias que se segue constituem os elementos principais comuns a ambas as peças, uma vez que Gnattali e Nazareth transitam por caminhos harmônicos distintos. Mas há ainda outro vínculo, um motivo elaborado a partir de um desenho de apogiaturas presente na primeira me-

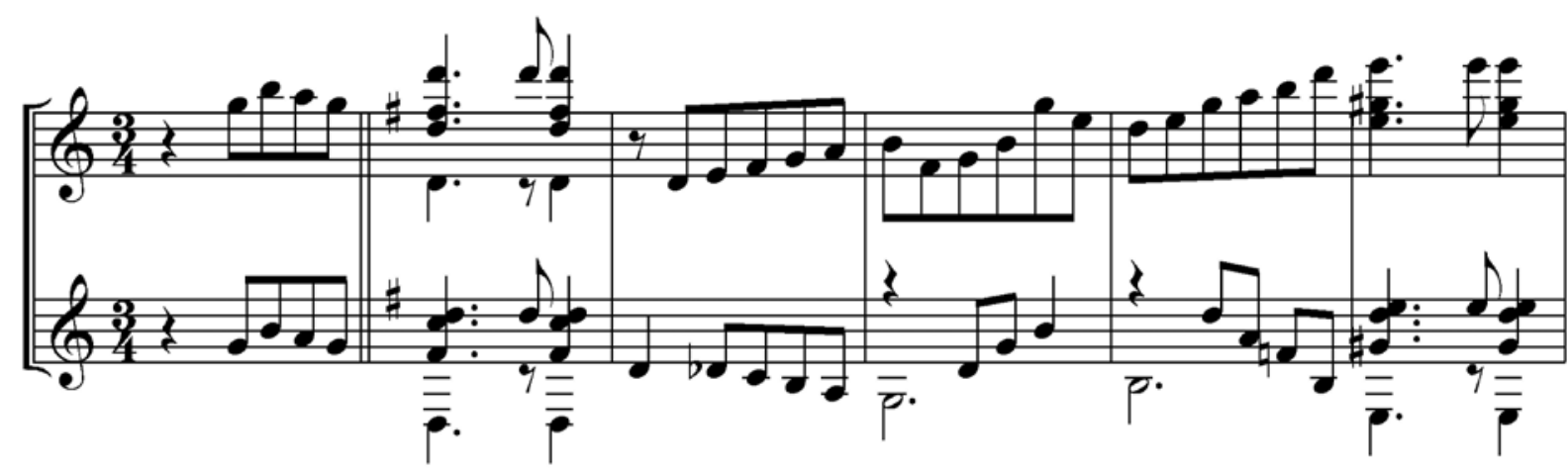

Ex.8: Retratos - valsa c.51-56 (início da seção B)

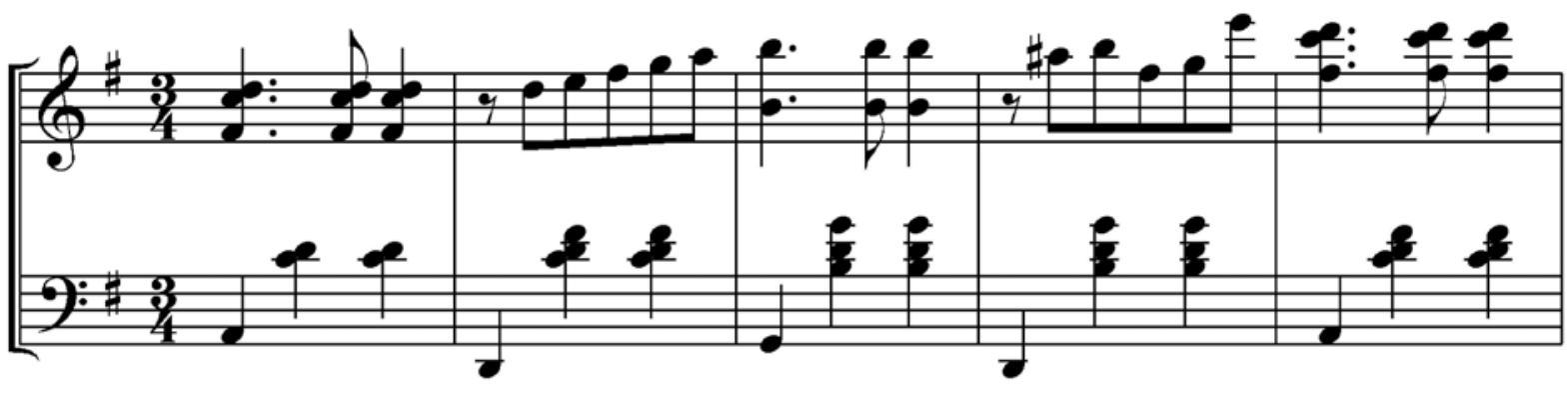

Ex.9: Expansiva c.33-37 (início da seção B)

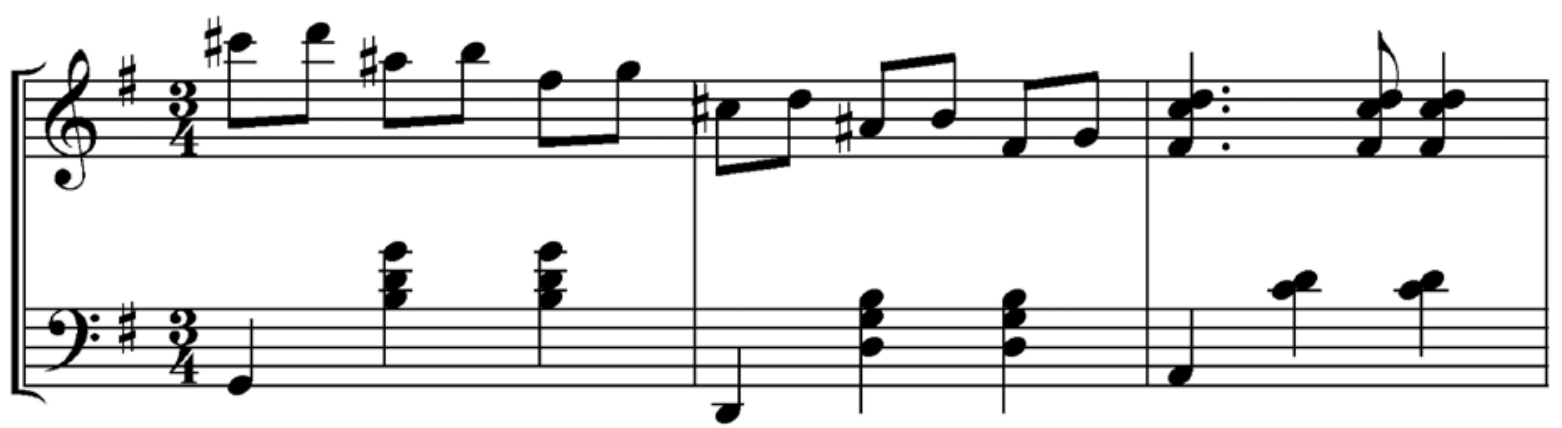

Ex.10: Expansiva c.39-41 (apogiaturas) 




Ex.11: Retratos - valsa c.62-64 (apogiaturas)

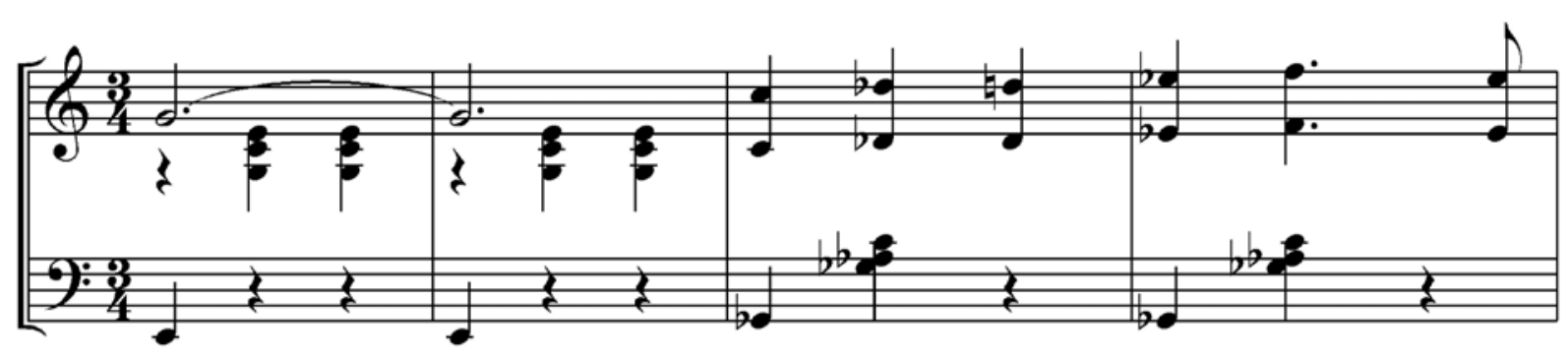

Ex.12: Expansiva c.23-26 (acorde de sexto grau abaixado em terceira inversão - c.25-26)



Ex.13: Retratos - valsa c.93-96 (acorde de sexto grau abaixado em segunda inversão - c.95)

tade da seção B de Expansiva (Ex.10). Neste trecho as apogiaturas ornamentam um arpejo descendente sobre a tônica, formando um grupo de dois compassos com a repetição do mesmo arpejo uma oitava abaixo.

Gnattali mantém o motivo das apogiaturas, mas inserido em outro ponto estrutural e em um contexto harmônico na dominante (Ex.11). Além disso, esta ideia é apresentada de uma forma mais curta na valsa de Retratos já que começa na segunda metade do primeiro compasso em questão.
Dentro da forma rondó, a seção A após a segunda parte em Expansiva é repetida exatamente como no início. $\mathrm{Na}$ valsa de Retratos, entretanto, este segundo A não segue as mesmas diretrizes estabelecidas pelo modelo. Conforme discutido anteriormente, Gnattali faz uma repetição abreviada de dezesseis compassos (exatamente a metade do esperado) e também muda o conteúdo melódico, dando-Ihe um caráter de variação temática com um contínuo fluxo de colcheias. 0 que é interessante é que neste ponto finalmente surge uma referência ao atraente acorde de sexto grau abaixado em terceira in- 
versão presente no final da seção A de Expansiva (Ex.12 c.25-26), mas apenas como um breve acorde de passagem (e em posição fundamental) para alcançar a tônica em segunda inversão (Ex.13 c.95).

A terceira parte da valsa de Retratos é nitidamente desenvolvida a partir da seção equivalente de Expansiva, também iniciando no terceiro grau da escala (Ex.14 e Ex.15).

Esta frase em Expansiva, essencialmente um arpejo construído sobre o primeiro grau, projeta-se através de um grande arco ascendente partindo de um Lá-2 até alcançar um Ré-6, totalizando uma extensão de três oitavas e uma quarta justa. Em contraste à exuberante fartura de um piano, a extensão prática de um bandolim não passa de três oitavas (e ainda assim de Sol-2 a Sol-5). Gnattali busca então outra solução para transmitir a sensação de movimento gerada pelo trânsito das diferentes oitavas, e o resultado é realizado através de um ritmo harmônico mais acelerado. Desta forma, observa-se que no início da terceira parte de Expansiva o movimento melódico é mais acentuado e a harmonia mais estática (Nazareth simplesmente alterna a posição fundamental com sua segunda inversão); inversamente, a valsa de Retratos apresenta no mesmo trecho um contorno melódico mais contido, mas com um movimento harmônico variado em cada compasso.

Nazareth faz desta seção um grande moto perpétuo valendo-se de uma malha costurada por colcheias do começo ao fim. Gnattali, entretanto, interrompe o fluxo inicial de colcheias com valores rítmicos diferenciados, criando uma atmosfera de caráter improvisatório muito peculiar ao seu estilo. No exato instante onde isto acontece (c.110) a harmonia volta a reproduzir o conteúdo do modelo, como se procurasse de alguma forma compensar a transformação melódica para que a música ainda permanecesse conectada à fonte (Ex.16).

Na sequência, o segundo grupo de dezesseis compassos (c.118) começa exatamente como o primeiro, da mesma forma que Nazareth procede em Expansiva. Apesar do fato de ambas as peças apresentarem um tratamento harmônico distinto neste início de frase, elas acabam se reencontrando no mesmo acorde diminuto que prepara 0 desfecho cadencial (Ex.17 e Ex.18).

A única diferença é o uso do primeiro grau em segunda inversão após o acorde diminuto em Expansiva, o qual é

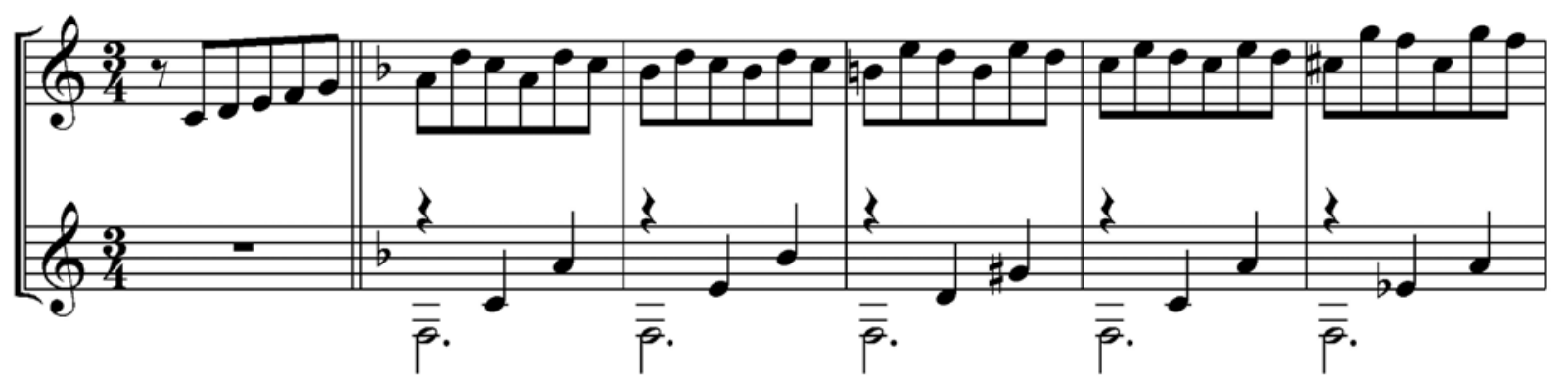

Ex.14: Retratos - valsa c.101-106 (início da seção C)



Ex.15: Expansiva c.97-101 (início da seção C) 

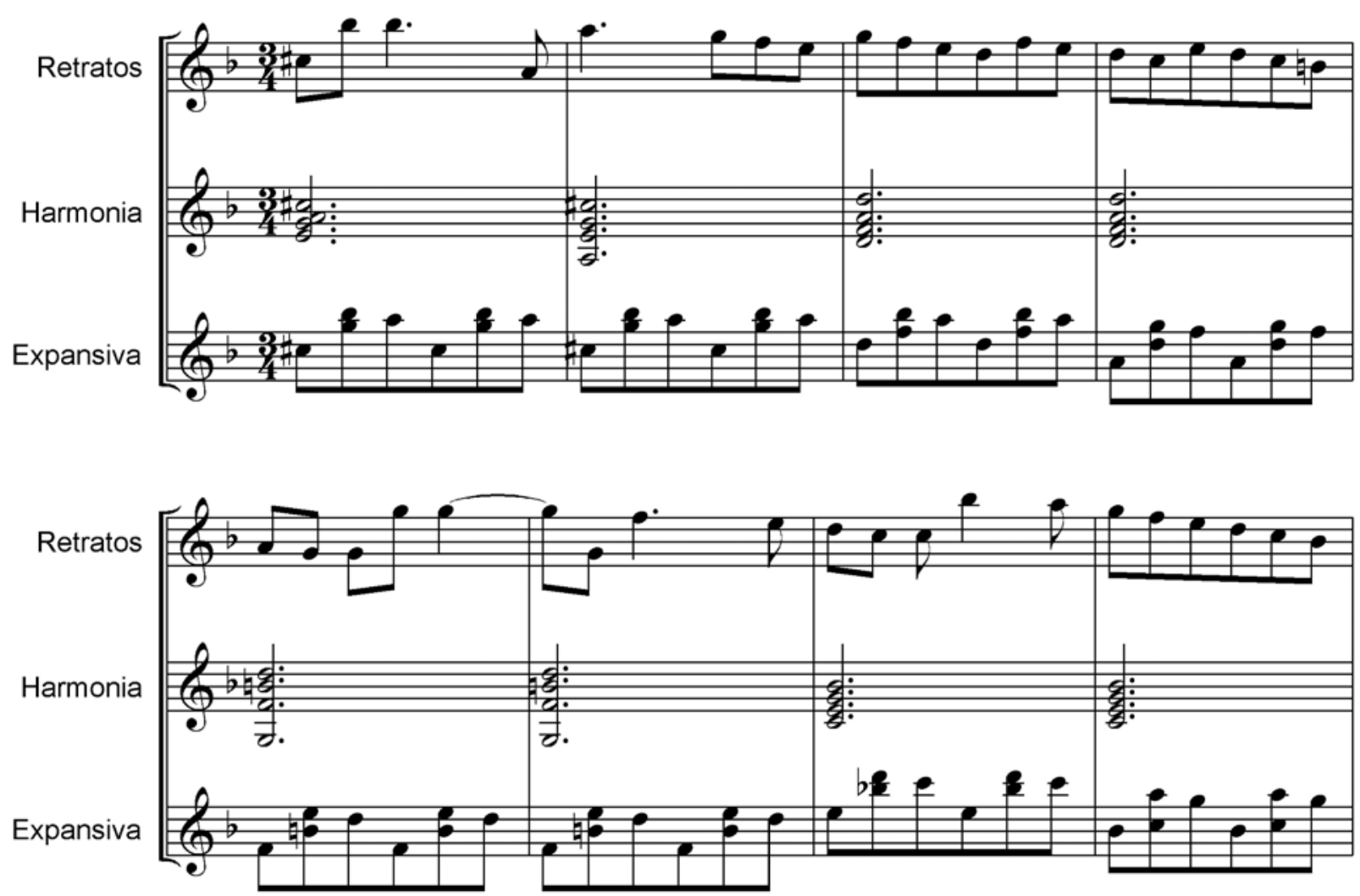

Ex.16: Harmonia compartilhada: Retratos -valsa (c.110-117) e Expansiva (c.105-112)

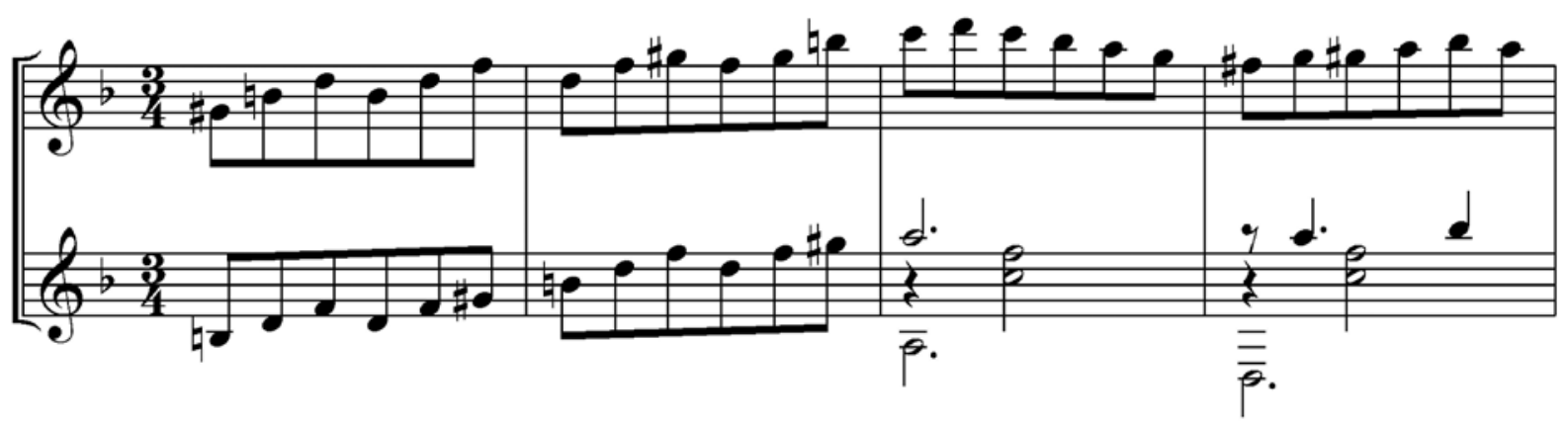

Ex.17: Retratos - valsa c.126-129 (acorde diminuto)



Ex.18: Expansiva c.121-124 (acorde diminuto) 
substituído na valsa da suíte pela primeira inversão seguida do sexto grau antes das dominantes finais.

Um detalhe relacionado ao aspecto formal é que ambos os compositores apresentam leituras diferentes no que diz respeito às repetições dentro da estrutura rondó. Em Expansiva, por exemplo, Nazareth não requer uma repetição para a terceira parte; Gnattali, entretanto, preserva o padrão tradicional repetindo esta seção, compensando de certa forma a inserção abreviada da seção A que antecede a terceira parte. De fato, esta repetição na valsa de Retratos surte um efeito de maior contraste em virtude de uma textura mais dinâmica em comparação ao movimento contínuo de $E x$ pansiva. Finalmente, a re-exposição da primeira parte encerra a moldura da forma rondó. Seguindo o mesmo procedimento usado no movimento anterior, Pixinguinha (choro), a valsa também termina com uma Codeta. Mas, enquanto que no choro a Codeta acrescenta material novo à estrutura, na valsa ela é inserida de modo que apenas completa a frase anterior, incorporando rigorosamente a mesma sequência harmônica dentro do mesmo espaço de cinco compassos.

\section{4- Considerações finais}

É fascinante como Gnattali atinge na valsa da suite um resultado com uma identidade própria tão marcante sendo ainda tão fiel ao modelo escolhido, a valsa Expansiva (esta afirmação, aliás, estende-se para os demais movimentos de Retratos e seus respectivos modelos). Para alguém que tem intimidade com o repertório do choro, uma primeira impressão ao ouvir esta obra mostra algo de familiar, deixando uma ligeira sensação de déjà vu. Traçando o caminho inverso do processo da composição, uma análise mais detalhada revela um mapa onde os caminhos percorridos por Gnattali e Nazareth se cruzam no momento da criação. E a originalidade de Retratos encontra-se exatamente nesta fronteira de contrastes: música de concerto, mas com raizes no choro, desde a escolha dos modelos e da instrumentação até a figura do solista. Sob o ponto de vista interpretativo, um estudo comparativo entre os retratos e os modelos contribui para o esclarecimento de vários problemas que surgem ao executar obras com este perfil, onde um dos maiores desafios é saber equilibrar os elementos das esferas popular e de concerto.

\section{Referências}

ANDRADE, Mário de. Música, doce música. São Paulo: Livraria Martins Editora, 1976.

BARBOSA, Valdinha; DEVOS, Anne Marie. Radamés Gnattali: o eterno experimentador. Rio de Janeiro: Funarte, 1984.

CARVALHO, Hermínio Bello de. In: GNATTALI, Radamés. Tributo a Jacob do Bandolim. São Paulo: ATLANTIC BR 20.055, 1980. 1 disco sonoro.

CAZES, Henrique. Choro: Do Quintal Ao Municipal. São Paulo: Ed.34, 1998.

DIDIER, Aluísio. Radamés Gnattali. Rio de Janeiro: Brasiliana, 1996.

GNATTALI, Radamés. Suite Retratos. Ed. Sérgio and Odair Assad. Paris: Henry Lemoine, 1987. 1 partitura (20p.). Dois violões.

LIMA, Luciano Chagas. Radamés Gnattali e Pixinguinha: Carinhoso no Choro da Suite Retratos. Anais do Simpósio de Pesquisa em Música, Curitiba, SIMPEMUS5, p.1-5, 2008.

NAZARETH, Ernesto. Expansiva. Rio de Janeiro: Irmãos Vitale, 1939. 1 partitura (4p.). Piano.

PAZ, Ermelinda A. Jacob do Bandolim. Rio de Janeiro: Funarte, 1997.

PINTO, Aloysio de Alencar. In: Revista Brasileira de Música 6. Rio de Janeiro: Editora e Gráfica Polar, 1963.

RANGEL, Lúcio. In: GNATTALI, Radamés. Retratos - Jabob e seu Bandolim com Radamés Gnattali e Orquestra. São Paulo: CBS 60099, 1964. 1 disco sonoro.

\section{Leitura recomendada}

BÉHAGUE, Gerard. The Beginnings of Musical Nationalism in Brazil. Detroit: Information Coordinators, 1977. Music in Latin America: An Introduction. Englewood Cliffs: Prentice-Hall, 1979.

"Nazareth, Ernesto." The New Grove Dictionary of Music and Musicians, ed. Stanley Sadie and John Tyrrell. London: MacMillan, 2001. Vol. 17: 720-721. 


\section{Discografia recomendada}

ALMEIDA, Laurindo; BARBOSA-LIMA, Carlos; BYRD, Charlie. Music of the Brazilian Masters. Estados Unidos: Concord Jazz 4389, 1989. 1 CD.

ASSAD, Sérgio e Odair. Duo Assad - Gnattali, Rodrigo, Piazzolla. São Paulo: Con Anima 004-1988, 1988. 1 disco sonoro. Latin American Music for Two Guitars. Holanda: Nonesuch 79116, 1992. 1 CD.

Alma Brasileira. Holanda: Nonesuch Records 79179, 1988. 1 CD.

BITTENCOURT, Jacob. Jacob Revive Músicas de Ernesto Nazareth. Rio de Janeiro: RCA Victor BP-1, 1952. 1 disco sonoro. Valsas Brasileiras de Antigamente. Rio de Janeiro: RCA Victor BBL 1100, 1960. 1 disco sonoro.

CANAUD, Fernanda; NASCIMENTO, Joel. Valsas Brasileiras. Rio de Janeiro: Biscoito Fino, 2008. 1 CD.

GNATTALI, Radamés. Ernesto Nazareth. Rio de Janeiro: Continental, LP-V-2001, 1954. 1 disco sonoro. . Retratos - Jabob e seu Bandolim com Radamés Gnattali e Orquestra. São Paulo: CBS 60099, 1964. 1 disco sonoro.

Tributo a Jacob do Bandolim. São Paulo: Atlantic BR 20.055, 1980. 1 disco sonoro.

LIMA, Arthur Moreira. Arthur Moreira Lima Interpreta Ernesto Nazareth n.2. São Paulo: Marcus Pereira MPA 9364/65, 1977. 1 disco sonoro duplo.

NASCIMENTO, Joel. Joel Nascimento and the Brazilian Sextet, Live! Estados Unidos: Santa Fe Chamber Music Festival, 1990. 1 CD.

NOGUEIRA, Gisela; COSTA, Gustavo. Tocata Brasileira para Pinho e Arame. São Paulo: CPC - UMES, 1998. 1 CD.

OFICINA DE CORDAS. Oficina de Cordas apresenta Retratos em Vários Compassos. Campinas: Ministério da Cultura / Secretaria da Música e Artes Cênicas, 2001. 1 CD.

ORQUESTRA ARMORIAL. Orquestra Armorial - vol 5. Pernambuco: Conservatório Pernambucano de Música, 1981. 1 disco sonoro.

ORQUESTRA DE CÂMARA RIO STRINGS. Retratos do Brasil. Rio de Janeiro: Rádio MEC, 2004. 1 CD.

RABELLO, Rafael. Rafael Rabello. Rio de Janeiro: Visom LPVO 018, 1988. 1 disco sonoro.

TRIO OPUS 12; NÚCLEO HESPÉRIDES MÚSICA DAS AMÉRICAS. Retratos de Radamés. São Paulo: Produção Independente, 2007. 1 CD.

VÁRIOS. Pixinguinha 70. Rio de Janeiro: Copacabana COLP 12118, 1968. 1 disco sonoro.

Retratos: Radamés Gnattali. Rio de Janeiro: Kuarup Discos KLP 044, 1990. 1 disco sonoro.

Prêmio Visa de MPB Instrumental. São Paulo: Eldorado, 1998. 1 CD.

Ao Jacob, Seus Bandolins. Rio de Janeiro: Biscoito Fino, 2003. 1 CD duplo.

Luciano Lima é Doutor (D. Mus.) pela Université de Montréal (Canadá), Mestre pela McGill University (Canadá) e Bacharel em violão pela Escola de Música e Belas Artes do Paraná. Como pesquisador, defendeu sua tese de doutorado sobre os Quatro Concertos para Violão Solo de Radamés Gnattali, além de ter artigos publicados em anais de eventos acadêmicos como XIX Congresso da ANPPOM, SIMPEMUS 5, e II Simpósio Acadêmico de Violão da Embap. Fez parte do quadro de professores da École des jeunes e do Service d'activités culturelles da Université de Montréal, no Canadá, e também das $20^{a}, 27^{a}$ e $28^{a}$ edições da Oficina de Música de Curitiba, do 29 Festival de Música de Londrina e do III Simpósio Acadêmico de Violão da Embap. Conciliado às atividades de ensino e pesquisa, Luciano desenvolve carreira como arranjador, solista e camerista, tendo se apresentado no Canadá, Estados Unidos e Brasil. 